\title{
SKIN METASTASES: THREE-YEAR STUDY OF 50 CASES IN A UNIVERSITY CENTER
}

\author{
Diana BELCIU1,2, Oana M. PATRASCU ${ }^{2,3} \bowtie$, Florina NEACSU ${ }^{2,3}$, Camelia C. DIACONU ${ }^{1,2}$, \\ Samuel BODOARCA ${ }^{4}$, Mariana COSTACHE ${ }^{2,3}$
}

${ }^{1}$ Clinical Emergency Hospital of Bucharest, Bucharest, Romania

2 University of Medicine and Pharmacy „Carol Davila“, Bucharest, Romania

${ }^{3}$ University Emergency Hospital, Bucharest, Romania

${ }^{4}$ „Marius Nasta“ National Pneumophtisiology Institute, Bucharest, Romania

Received 15 Jan 2019, Accepted 22 Febr 2019

https://doi.org/10.31688/ABMU.2019.54.1.13

\section{Abstract}

Introduction. Skin metastases are rare metastases of internal or cutaneous tumors, commonly diagnosed after the primary cancer. Sometimes, they can be the first manifestation of a malignancy. Cutaneous metastases associate a poor prognosis for the patient and the survival rate decreases considerably.

The objective of the study was to analyse the clinico-epidemiological and histological characteristics of skin metastases, in order to better understand different types of malignancies and their prognosis, as well as to highlight the particularities of this rare localization of the metastases.

Material and methods. We conducted a retrospective study, in which we included 50 cases of skin metastases diagnosed in the Pathology Department of the University Emergency Hospital Bucharest, Romania, over a period of three years. We analysed the cases from all epidemiological, clinical, gross and histological data, based on the records of the hospital.

Results. The patients' ages ranged from 16 to 92 years old, with a mean age of 60.1 years. Almost half of the

\section{Résumé}

Métastases cutanées: étude de 50 cas dans un centre universitaire pour une période de trois ans

Introduction. Les métastases cutanées sont des déterminations rares de tumeurs internes ou cutanées, généralement diagnostiquées après le cancer primitif. Néanmoins, elles peuvent, parfois, être la première manifestation d'une tumeur maligne. Les métastases cutanées associent un mauvais pronostic au patient et le taux de survie diminue considérablement.

Objectifs. Les objectifs de l'étude étaient d'analyser et d'évaluer les caractéristiques cliniques-épidémiologiques et histologiques afin de mieux comprendre les différents types de tumeurs malignes et leur pronostic, ainsi que de mettre en évidence la rareté de cette localisation particulière des métastases.

Matériel et méthodes. Nous avons mené une étude rétrospective dans laquelle nous avons inclus 50 cas de métastases cutanées diagnostiquées au département de Pathologie de l'hôpital Universitaire d'Urgence de Bucarest sur une période de trois ans. Nous avons 
patients were females (26 cases). Most of the patients were diagnosed with primary melanoma (17 cases), followed by primary tumors of the gastrointestinal tract ( 9 cases) and breast carcinomas ( 8 cases). 29 cases presented with complications, such as ulceration, infection or necrosis.

Conclusions. Most of the skin metastases were of malignant melanoma, but any kind of primary tumor can, eventually, disseminate to the skin, conferring a poor prognosis on the patient. Also, any site can be involved, but some malignancies do have preferred areas for dissemination.

Keywords: skin metastasis, cutaneous tumors, malignancy of the skin. analysé les cas à partir de toutes les données épidémiologiques, cliniques, globales et histologiques basées sur les dossiers de l'hôpital.

Résultats. L'âge du patient est compris entre 16 et 92 ans, avec une moyenne de 60,1 ans. Près de la moitié des patients étaient des femmes (26 cas). Un mélanome primitif (17 cas) a été diagnostiqué chez la plupart des patients, suivi de tumeurs primitives du tractus gastro-intestinal $(9 \mathrm{cas})$ et de carcinomes du sein $(8 \mathrm{cas})$. 29 cas présentaient des complications telles qu'une ulcération, une infection ou une nécrose.

Conclusions. La plupart des métastases cutanées étaient dues à un mélanome malin, mais tout type de tumeur primitive peut éventuellement se disséminer sur la peau, ce qui confère un mauvais pronostic au patient. En outre, n'importe quel site peut être impliqué, mais certaines tumeurs malignes ont des zones de prédilection pour la diffusion.

Mots-clés: métastases cutanées, tumeurs cutanées, tumeurs malignes de la peau.

but also for the correct and complete treatment of the disease ${ }^{14}$.

Cutaneous metastases are rare findings, frequently appearing after the primary tumor is diagnosed or even treated ${ }^{1}$. A metastasis is defined as the spread of malignant cells at a various distance from a primary tumor. These secondary tumors appear after the migration of tumor cells through lymphatic and blood vessels, but also through nerves, due to their ability to penetrate the extracellular matrix, to attach to different sites, subsequently degrading the membranes and penetrating in the vessels' walls ${ }^{2}$.

The incidence of skin metastasis ranges between $0.6-10 \%^{1,3,4}$, one meta-analysis determining an incidence of $5.3 \%{ }^{5}$. Regarding the primary site, the incidence of lung cancer metastasis on the skin was reported to be $1-12 \%{ }^{6}$. Although lung and breast carcinomas are considered the most frequent tumors to metastasize to the $\operatorname{skin}^{7,8}$, melanoma is also a leading cause of skin metastases, often representing the first sign of extranodal metastatic disease 9 . About $3.5 \%$ of ovary carcinomas metastasize to the skin ${ }^{10}$, whereas the renal carcinomas' skin metastases are extremely rare, with about 80 cases described in the literature ${ }^{11}$, although some studies reported that $6 \%$ of the skin metastases had a renal cell carcinoma as a primary tumor $^{12}$. Cutaneous disseminations secondary to pancreatic cancer do not exceed $2 \%$ from the total number of skin metastases ${ }^{13}$.

The early recognition of a metastasis is important for the prognosis of the patient, the survival rate,
The objective OF THE STUdy was to analyse the clinico-epidemiological and histological characteristics of skin metastases, in order to better understand the different types of malignancies and their prognosis, as well as to highlight the particularities of this rare localization of the metastases.

\section{Materials AND MEthods}

We conducted a retrospective study, over a period of three years (2013 to 2016). We included 50 cases diagnosed in the Pathology Department of the University Emergency Hospital Bucharest, Romania, with cutaneous metastases from various malignancies, including malignant melanoma. We noted all epidemiological, clinical and histological data, including age, environment, lesion's localization, gross dimensions or the presence of complications within the lesions.

The tissue samples were fixed with $10 \%$ buffered formalin and were processed by conventional histopathological methods using inclusion in paraffin, sectioning and Hematoxylin-Eosin (HE) staining. Gross examination included characteristics such as dimensions, appearance, consistency and color. Light microscopy examination revealed different aspects, depending on the primary tumor (malignant cells with histological characteristics of carcinomas or melanomas, arranged in cord, nests or with glandular, 


\section{Distribution by age in the group of study}

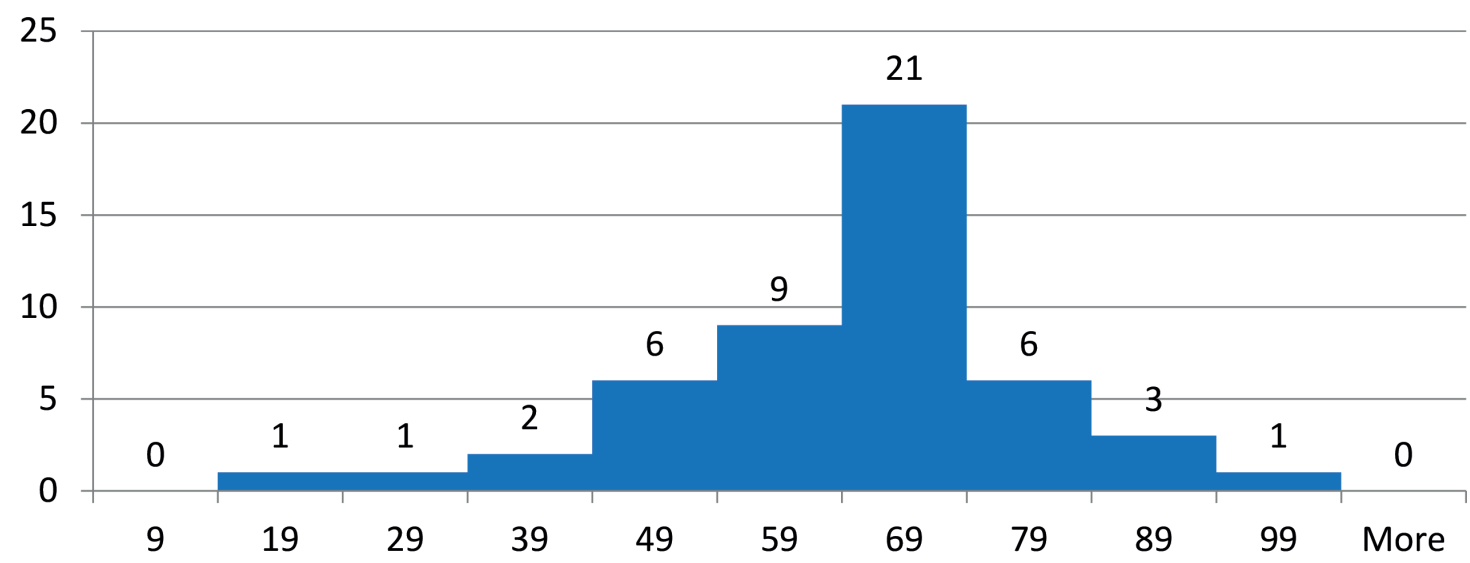

Fig. 1. The distribution by age.

\section{Primary tumor localization}

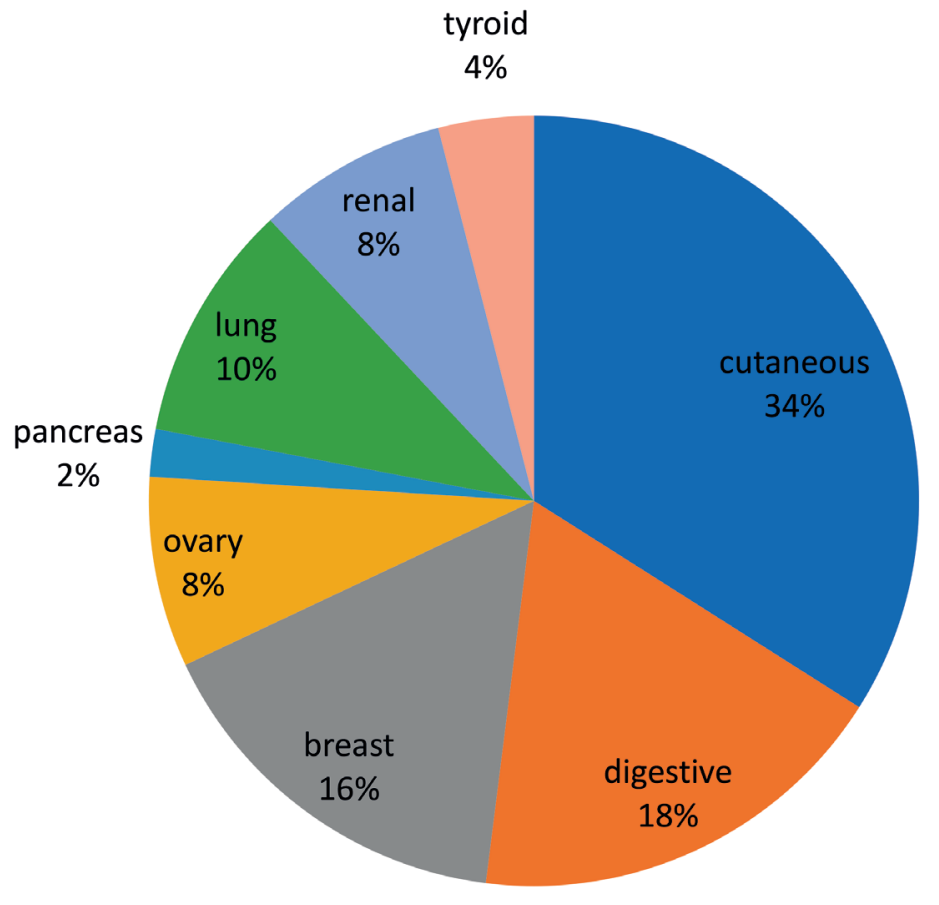

Fig. 2. The distribution by the localization of the primary tumor.

cribriform or solid patterns). Also, complications, if found, were noted.

Statistical tests were performed using Microsoft Office Excel 2007 - Data Analysis.

\section{Results}

From the 50 patients registered, about half were females (26 cases), and 27 cases were from rural areas. The ages varied from 16 to 92 years old (Fig. 1), with a mean age of 60.1 years.
Most of the primary tumors were of cutaneous origin, mostly malignant melanomas (17 cases), followed by tumors of gastrointestinal tract and breast carcinomas (9, respectively 8 cases). Ten percent of the skin metastases were of pulmonary origin, whereas $8 \%$ were from gynecological organs, namely of ovarian origin (Fig 2).

The majority of the patients had only one skin metastasis at the moment of the diagnosis, and 28\% of the cases presented with multiple skin disseminations. 


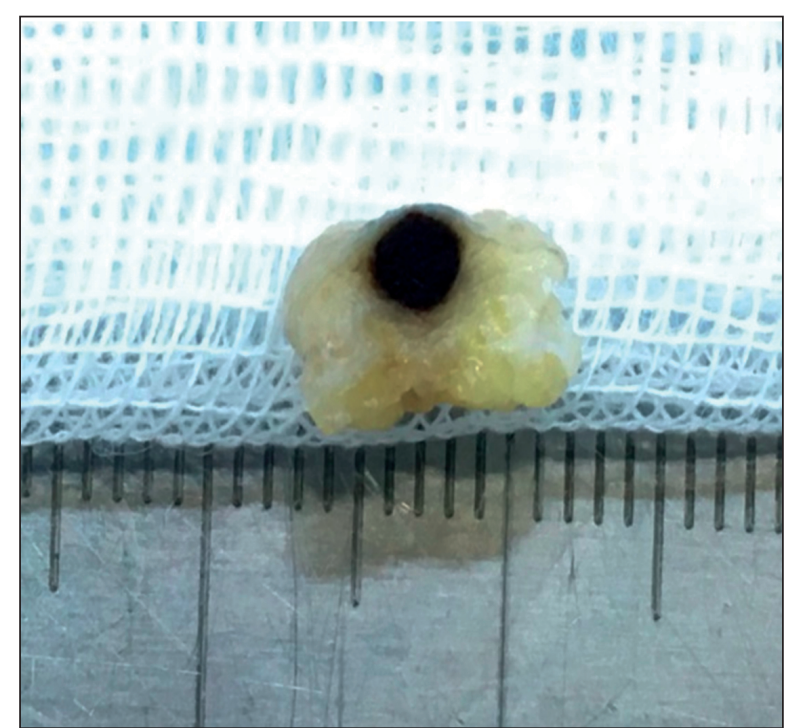

Fig. 3. Melanoma metastasis on gross section

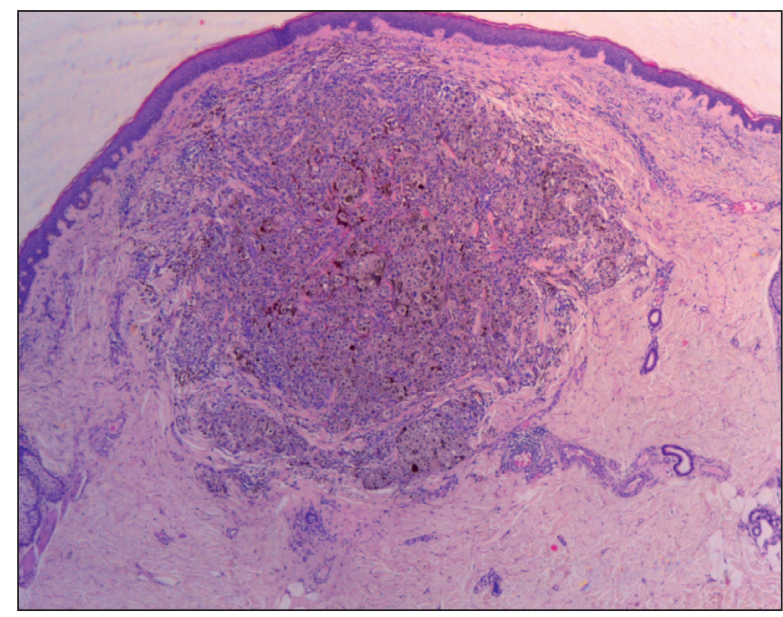

Fig. 5. Melanoma metastasis, with malignant melanocytes, with melanin in cytoplasm, localized in the superficial dermis, 40X, HE.

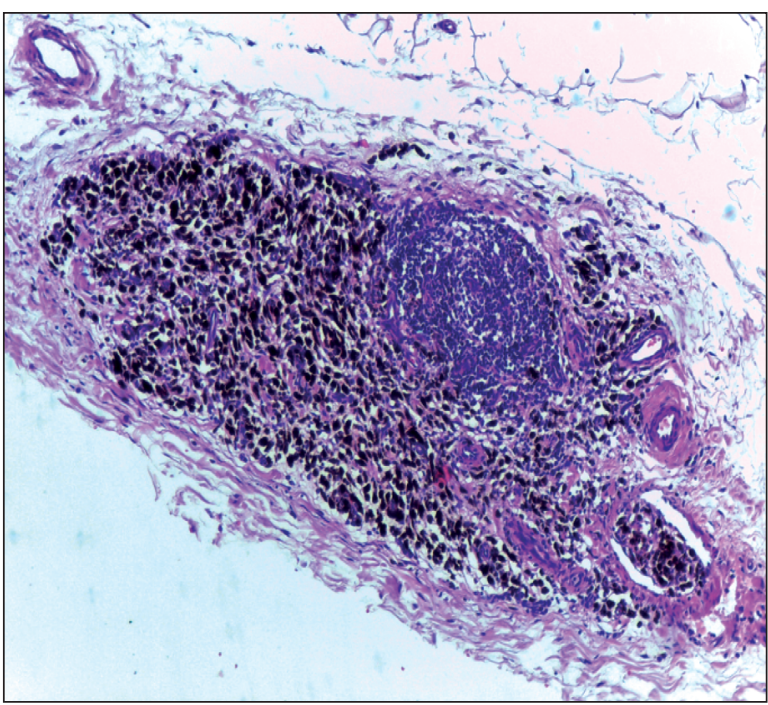

Fig. 7. Tumor embolus from a melanoma, 100X, HE

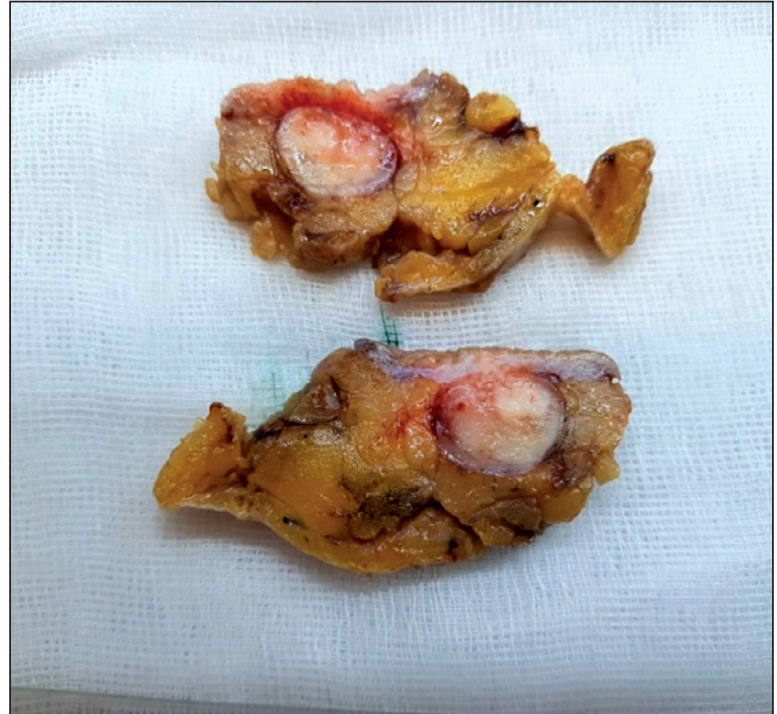

Fig.4. Skin metastasis (non-melanoma) on gross section

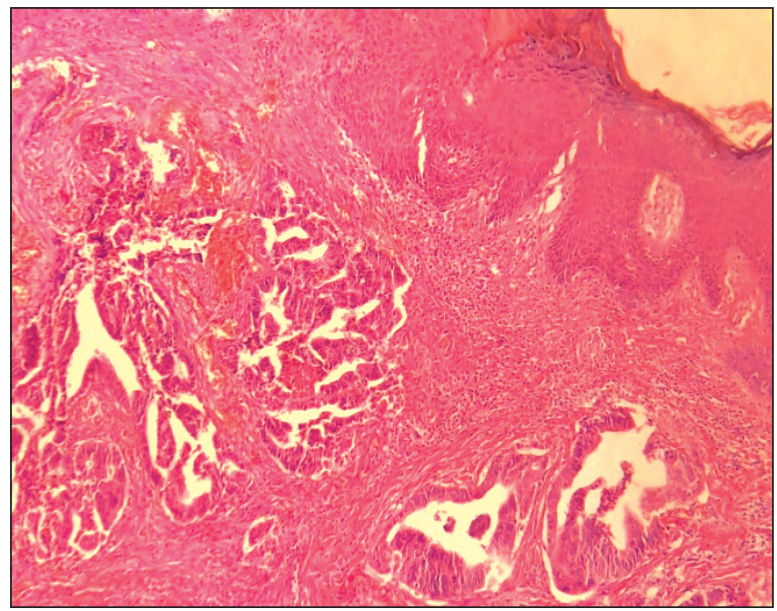

Fig. 6. Adenocarcinoma metastasis, glandular and cribriform structures invading the superficial dermis, 100X, HE.

Gross examination revealed different nodular lesions of the skin, localized mainly in the dermis and hypodermis, some presenting with superficial ulcerations. Most of the melanoma metastases were pigmented, with a brown-black color and with relatively circumferential borders (Fig.3). The rest of the cases were white -grey lesions (Fig. 4), some of nodular appearance, whereas some were fragmented. The dimensions varied from $7 \mathrm{~mm}$ to $100 \mathrm{~mm}$, with a mean gross dimension of $26.28 \mathrm{~mm}$. Also, we noted a statistically significant. but weak correlation $\left(\mathrm{r}_{(48)}=\right.$ $0,28, p=0.04)$. between the age of the patient and the dimensions of the lesions (regression function, Microsoft Excel 2007).

Histologically, after melanoma (Fig. 5), the second most frequent type of malignancy diagnosed as a skin metastasis was adenocarcinoma (Fig 6). 

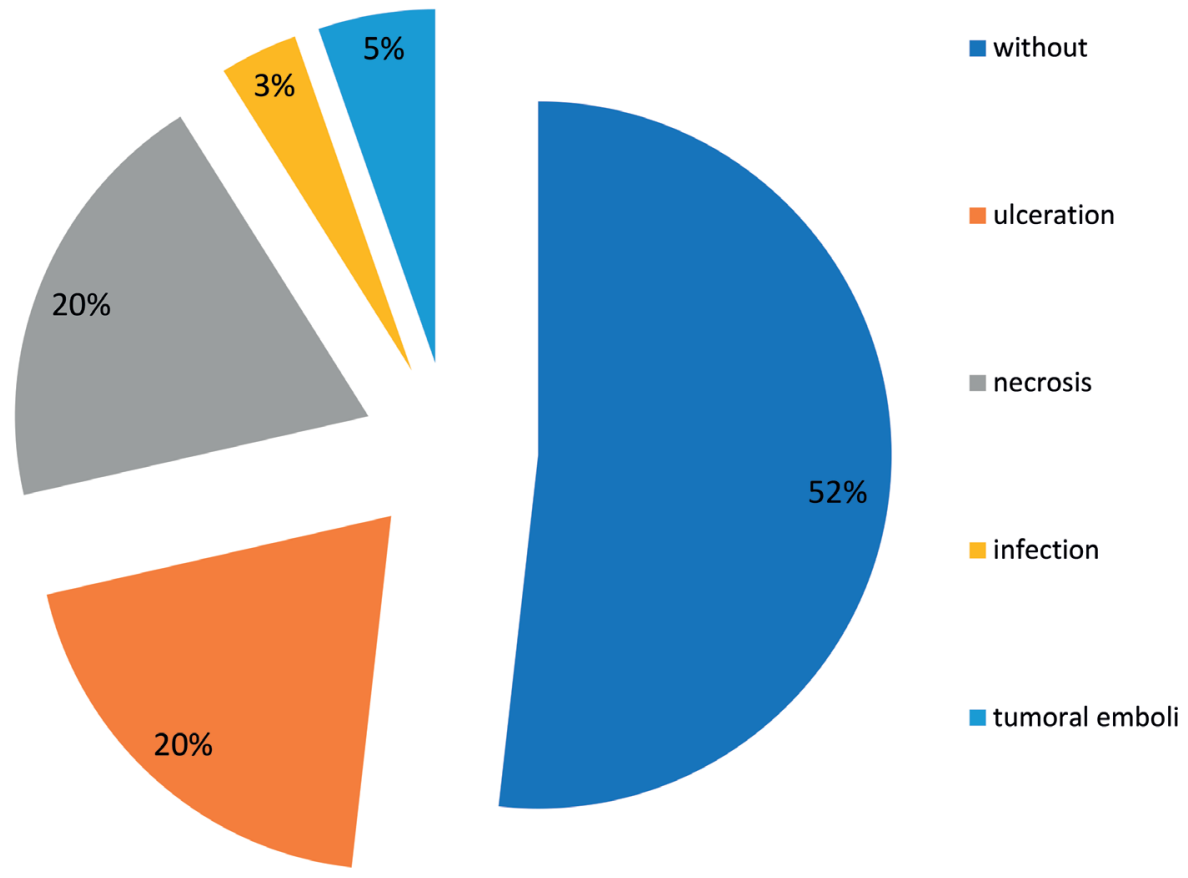

Fig. 8. Complications frequency

Distribution of skin metastases on anatomical areas

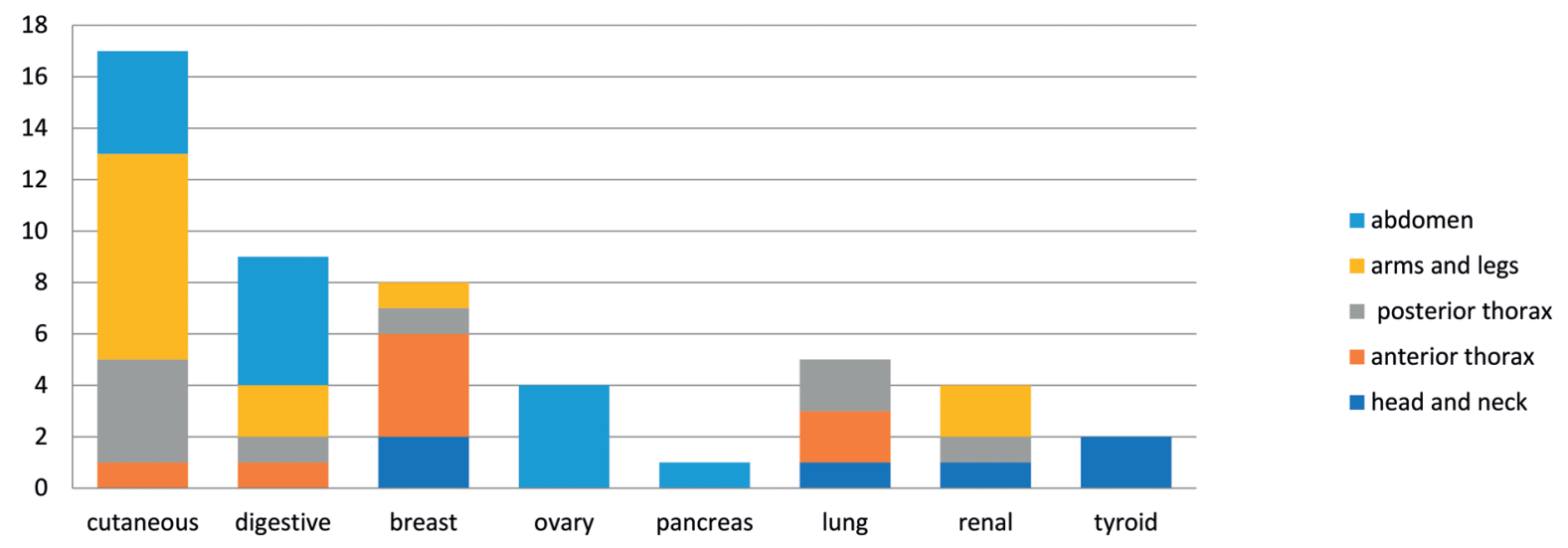

Fig. 9. Distribution of skin metastases on anatomical areas.

Furthermore, there were two clear cell carcinomas, one small cell carcinoma, two papillary cell carcinomas, one serous cell carcinoma and one cystadenocarcinoma with ovarian origin. Regarding the breast metastasis, four cases were typed ductal (NOS-not otherwise specified) carcinomas and two cases were lobular carcinomas. Squamous cell carcinoma was diagnosed in only three cases.

Twenty nine cases had no complications, whereas $20 \%$ of the cases presented with ulceration and/ or intratumoral necrosis. In three cases, tumoral emboli (Fig. 7) were reported and only two lesions were infected (Fig. 8).

Cutaneous primary tumors metastasized mainly in arms and legs, whereas digestive, ovary and pancreas adenocarcinomas metastases were preferentially found on the abdomen (Fig. 9). Interestingly, renal cell carcinomas metastases were found on the head and neck region, as well as on the arm and legs. Anterior and posterior thorax was the preferred area for lung and breast disseminations. All of the metastases with skin origin were diagnosed as melanomas, while from the digestive tract there were mostly adenocarcinomas, with only two squamous cell carcinomas. In the Figure 10, the types of tumors from various primary sites that had disseminated on the skin may be seen.

Regarding gender, 7 cases of skin metastases with cutaneous origin were identified in women, whereas 10 cases were diagnosed in men. Also, 8 


\title{
Distribution of primary tumors depending on the histological type
}

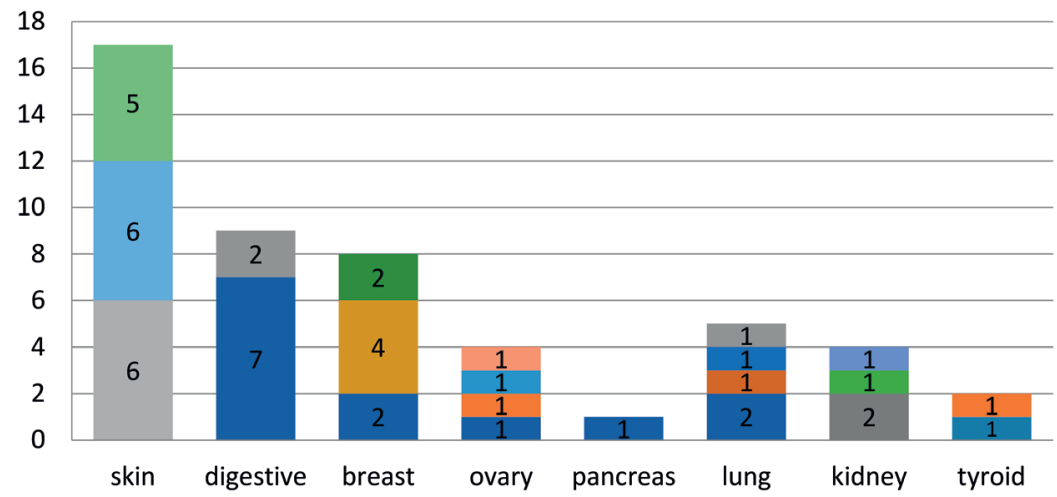

\author{
Nodular melanoma \\ Superficial spreading melanoma \\ - Acral melanoma \\ - Cystadenocarcinoma \\ - Tubulocystic carcinoma \\ - Tubular mucinous carcinoma \\ - Serous carcinoma \\ - Squamous cell carcinoma \\ - Papillary carcinoma \\ - Undifferentiated carcinoma \\ - Lobular carcinoma \\ - Folicular carcinoma \\ - Ductal carcinoma \\ - Clear cell carcinoma \\ - Small cell carcinoma \\ - Adenocarcinoma
}

Fig. 10. Distribution of primary tumors depending on the histological type.

cases of breast metastases and 4 cases originated from the ovary, while only 3 cases originated from the digestive tract, 2 cases had renal origin and one case of pancreas metastasis was encountered in a woman. On the other hand, we found 6 cases of skin metastasis from a digestive tumor, 5 cases originating from the lung and 3 renal metastases in men.

\section{Discussion}

The diagnosis of skin metastasis is relatively rare and does not, commonly, raise exceptional problems, as most of the patients have a known and treated primary tumor prior to the diagnosis. Although most of the metastases look like the primary tumor, there are cases in which a specific diagnosis cannot be made. Our study is one of the few made in Romania, and included an important number of skin metastasis (50 cases), some diagnosed only on hematoxilin-eosin staining, with a few requiring additional immunohistochemistry staining.

Most of the tumors examined in our study had a cutaneous origin, namely melanoma metastasis, a finding similar with other studies conducted so far ${ }^{1}$. Also, after melanoma, the most frequent types of metastases found in our study were of the breast and ovary carcinomas for females, and digestive and lung carcinomas in men, data which correlate with other studies ${ }^{1,14,15}$. In our study, the preferred areas for melanoma metastases were on arm, legs, but also on the thorax and abdominal wall, as various studies showed so far ${ }^{16}$.

Furthermore, in our study, breast metastases were frequently found on the anterior chest, a common place for this malignancy, as cited in the literature ${ }^{2,17}$, but also on the head and limbs. Lung carcinomas preferred the thorax and also the head and neck, whereas the digestive tract and ovary predilection for the abdomen was once again confirmed ${ }^{14}$.

We also found only one case of pancreatic skin dissemination, as the incidence is known to be very low ${ }^{13}$. Moreover, the site of metastasis was abdominal, a frequently cited area for this malignancy ${ }^{15}$.

Renal cell carcinoma metastasized on the skin of the head in one case, a common site for this tumor ${ }^{18}$, but we also found metastases on legs and thorax, areas that are rare findings for this malignancy.

Regarding the type of primary carcinoma, in our study, the most common malignancy of gastrointestinal tract that disseminated on the skin was adenocarcinoma, without knowing for sure the origin, followed by two cases of squamous cell carcinomas. Moreover, $50 \%$ of the renal carcinomas disseminated to the skin were of clear cell-type, the most common histological renal carcinoma type cited in the literature ${ }^{18}$, whereas for the breast the most frequent type of carcinoma was the ductal (NOS) carcinoma.

In contrast with some studies found in the literature $^{14}$, but in agreement with others ${ }^{19}$, the majority of the patients included in our study presented only one lesion on the skin. Some of the lesions were of nodular type, brown or whitish, depending on the primary tumor, while other lesions were fragmented and hard to examine. More than a half of the cases did not present any complications, with $20 \%$ of the lesions presenting with ulceration or necrosis, and only $5 \%$ with vascular invasion, percentages lower than those found in the literature ${ }^{20}$. 


\section{Conclusions}

Malignant melanoma was the most common primary tumor metastasized on the skin, but any histological type can eventually disseminate to the skin. Also, any site can be involved, but some malignancies do have preferred areas for dissemination.

Overall, skin metastases are a marker of a poorer prognosis and a decreased survival rate. However, an early detection can change the treatment and the quality of the patient's life. Even if most of the skin metastases appear in the late stage of the malignant disease, in some cases the skin metastases could represent the first sign of malignancy or a sign of disease recurrence.

\section{Compliance with Ethics Requirements:}

„The authors declare no conflict of interest regarding this article"

"The authors declare that all the procedures and experiments of this study respect the ethical standards in the Helsinki Declaration of 1975, as revised in 2008(5), as well as the national law. Informed consent was obtained from all the patients included in the study"

"No funding for this study"

\section{References}

1. Nibhoria S, Tiwana KK, Kaur M, Kumar S, A Clinicopathological and immunohistochemical correlation in cutaneous metastases from internal malignancies: a five-year study. Journal of Skin Cancer. 2014; Article ID 793937.

2. Mordenti C, Peris K, Concetta M, Fargnoli L, Cerroni L, Chimenti S. Cutaneous metastatic breast carcinoma: A study of 164 patients. Acta Dermatoven APA. 2000;9(4):143-148.

3. Goyal N, Pai K, Pai SB, Jaiprakash PP. Clinicopathological profile of cutaneous metastasis from internal malignancies: a five year retrospective study. Journal of Clinical and Diagnostic Research. 2018;12(1):WC01-WC03.

4. Handa U, Kundu R, Dimri K. Cutaneous metastasis: a study of 138 cases diagnosed by fine-needle aspiration cytology. Acta Cytologica 2017;61:47-54.
5. Krathen RA, Orengo IF, Rosen T. Cutaneous metastasis: a meta-analysis of data. South Med J. 2003;96(2):164-7.

6. Mollet TW, Garcia CA, Koester G. Skin metastases from lung cancer. Dermatol Online J. 2009;15(5):1.

7. Wong CY, Helm MA, Helm TN, Zeitouni N. Patterns of skin metastases: a review of 25 years' experience at a single cancer center. Int J Dermatol. 2014;53(1):56-60.

8. Hussein MR. Skin metastasis: a pathologist's perspective. J Cutan Pathol. 2010;37(9):e1-20.

9. Lookingbill DP, Spangler N, Helm KF. Cutaneous metastases in patients with metastatic carcinoma: a retrospective study of 4020 patients. J Am Acad Dermatol. 1993;29(2 Pt 1):228-36.

10. McDonald HH, Moore MR, Meffert JJ. Cutaneous metastases from adenocarcinoma of the ovary. JAAD Case Rep. 2016; 2(5): 406-407.

11. Terada T. Cutaneous metastasis of renal cell carcinoma: a report of two cases. Int J Clin Exp Pathol. 2012; 5(2):175-178.

12. Porter NA, Anderson HL, Saad Al-Dujaily. Renal cell carcinoma presenting as a solitary cutaneous facial metastasis: case report and review of the literature. Int Semin Surg Oncol. 2006; 3: 27.

13. Horino K, Takamori H, Ikuta Y, et al. Cutaneous metastases secondary to pancreatic cancer. World J Gastrointest Oncol. 2012;4(7):176-80.

14. Gul U, Kilic A, Gonul M, Kulcu Cakmak S, Erinckan C. Spectrum of cutaneous metastases in 1287 cases of internal malignancies: a study from Turkey. Acta Derm Venereol. 2007:87:160-162.

15. Oualla K, Arifi S, Mellas N, El Mesbahi O. Cutaneous metastases of internal cancers: a retrospective study about 12 cases. J Cancer Sci Ther. 2012;4:155-157.

16. Savoia P, Fava P, Bernengo MG. Cutaneous metastases from malignant melanoma: clinical features and new therapeutic perspectives, treatment of metastatic melanoma. 2011, Rachael Morton (ed.), IntechOpen. Available from: https:// www.intechopen.com/books/treatment-of-metastatic-melanoma/cutaneous-metastases-from-malignant-melanoma-clinical-features-and-new-therapeutic-perspectives/

17. Nava G, Greer K, Patterson J, Lin KY. Metastatic cutaneous breast carcinoma: A case report and review of the literature. Can J Plast Surg. 2009;17(1):25-7.

18. Dorairajan LN, Hemal AK, Aron M, et al. Cutaneous metastases in renal cell carcinoma. Urol Int. 1999;63(3):164-7.

19. Khoury EJ, Khalifeh I, Kibbi AG, Abbas O. Cutaneous metastasis: clinico-pathological study of 72 patients from a tertiary care center in Lebanon. International Journal of Dermatology. 2014;53(2):147-158.

20. Fernandez-Flores A. Cutaneous metastases: a study of 78 biopsies from 69 patients. Am J Dermatopathol. 2010;32(3):222-39. 